\title{
T oints
}

$\sqrt{01}$

\section{Reverse total shoulder arthroplasty: research models}

\author{
STEFANO PETRILLO ${ }^{1,2}$, UMILE GIUSEPPE LONGO1,2, LAWRENCE V. GULOTTA ${ }^{3}$, \\ ALESSANDRA BERTON ${ }^{1,2}$, ANDREAS KONTAXIS ${ }^{4}$, TIMOTHY WRIGHT ${ }^{3}$, VINCENZO DENARO ${ }^{1,2}$ \\ ${ }^{1}$ Department of Orthopaedic and Trauma Surgery, Campus Bio-Medico University, Trigoria, Rome, Italy \\ ${ }^{2}$ Centro Integrato di Ricerca (CIR) Campus Bio-Medico University, Trigoria, Rome, Italy \\ ${ }^{3}$ Sports Medicine and Shoulder Service, Hospital for Special Surgery, New York, USA \\ ${ }^{4}$ Leon Root, Motion Analysis Laboratory, New York, USA
}

\begin{abstract}
Purpose: the past decade has seen a considerable increase in the use of research models to study reverse total shoulder arthroplasty (RTSA). Nevertheless, none of these models has been shown to completely reflect real in vivo conditions.

Methods: we performed a systematic review of the literature matching the following key words: "reverse total shoulder arthroplasty" or "reverse total shoulder replacement" or "reverse total shoulder prosthesis" and "research models" or "biomechanical models" or "physical simulators" or "virtual simulators". The following databases were screened: Medline, Google Scholar, EMBASE, CINAHIL and Ovid. We identified and included all articles reporting research models of any kind, such as physical or virtual simulators, in which RTSA and the glenohumeral joint were reproduced.

Results: computer models and cadaveric models are the most commonly used, and they were shown to be reliable in simulating in vivo conditions. Bone substitute models have been used in a few studies.

Mechanical testing machines provided useful information on stability factors in RTSA.

Conclusion: because of the limitations of each individual model, additional research is required to develop a research model of RTSA that may reduce the limita-

\section{Corresponding Author:}

Umile Giuseppe Longo, MD, MSc, PhD

Department of Orthopaedic and Trauma Surgery, Campus Bio-Medico University

Via Alvaro del Portillo 200, 00128 Trigoria, Rome, Italy

E-mail: g.longo@unicampus.it
\end{abstract}

tions of those presently available, and increase the reproducibility of this technique in the clinical setting.

Keywords: arthroplasty, research model, reverse, shoulder, simulator.

\section{Introduction}

Reverse total shoulder arthroplasty (RTSA) is, essentially, a technique that converts the humerus into a socket and the glenoid into a ball with a congruency that guarantees greater joint stability in order to compensate for a dysfunctional rotator cuff (RC) (1).

Nevertheless, its results are discordant, and differences in outcomes, range of motion ( $\mathrm{ROM}$ ), and stability after RTSA may be related to various factors: the specific implant geometry and design (2), the surgical technique, the underlying disease (3-9), and the functionality of available residual RC tissue in the single patient (10-15). To better understand these factors, several Authors have developed models of the shoulder for the purpose of studying the main characteristics of various RTSA designs (10-12, 16-32).

These research models can be divided into two main categories: physical simulators and virtual simulators. Physical simulators consist of either cadaver shoulders, or models of shoulders made from a synthetic material designed to replicate the properties of bone. Virtual simulators are computer models. These can be twodimensional (2D) or three-dimensional (3D) and they are designed to evaluate, in a virtual manner, the influence of RTSA on joint ROM through computer reconstruction of previously validated anatomical, mechani- 
cal or cadaveric models. These various models can be helpful for understanding the surgical and implant design variables that can have an important impact on the outcomes of RTSA procedures. The aim of this study is to summarize the available research models that have been used to evaluate RTSA.

\section{Methods}

A systematic review of the literature was performed matching the following key words: "reverse total shoulder arthroplasty" or "reverse total shoulder replacement" or "reverse total shoulder prosthesis" and "research models" or "biomechanical models" or "physical simulators" or "virtual simulators". The last search was performed on $13^{\text {th }}$ March 2016. The following databases were screened: Medline, Google Scholar, EMBASE, CINAHIL and Ovid. Two independent reviewers (SP and UGL) performed a blind search. All relevant peer-reviewed articles were analyzed and all journals were considered. The inclusion and exclusion criteria are listed in Table 1.

\section{Results}

The literature search and cross-referencing resulted in a total of 21 articles $(10-12,16-33)$ eligible for this review (Fig. 1). The results of the review are descri- bed below, dividing the RTSA research models identified by category: 1) physical simulators (cadaver models, bone substitute models, mechanical testing machines); 2) virtual simulators (2D or 3D computer models) (Tabs. 2, 3).

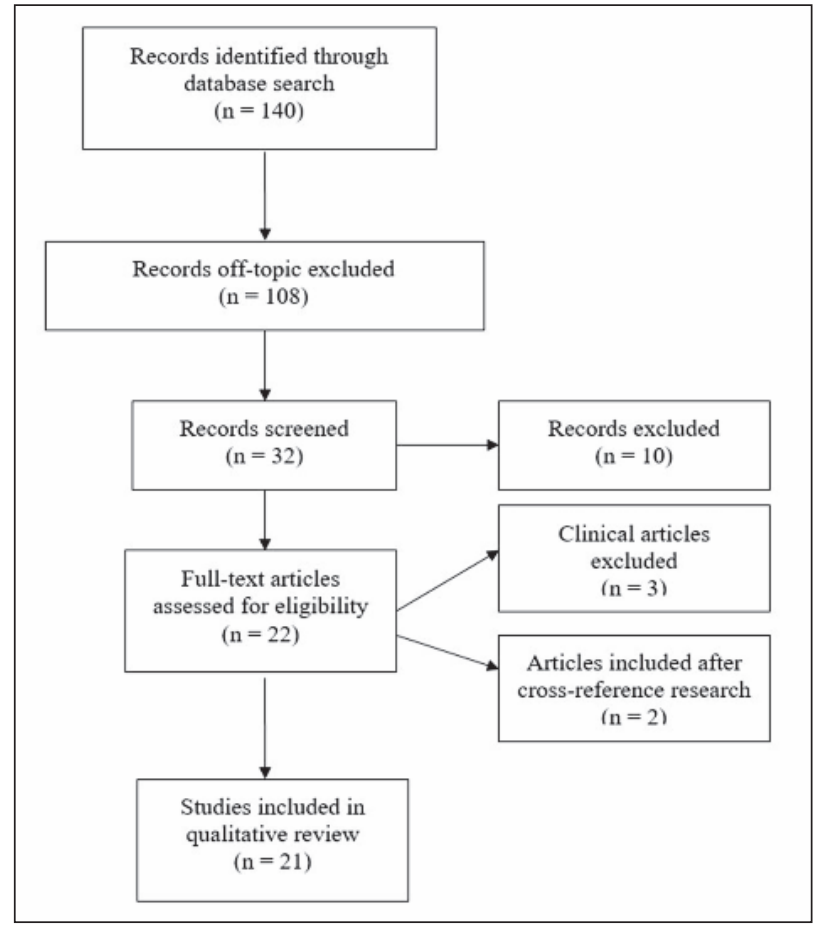

Figure 1. Literature search algorithm.

Table 1. Literature search.

\section{DATABASES}

ARTICLE LANGUAGES

LEVELS OF EVIDENCE ACCEPTED

KEY WORDS MATCHED

\section{ARTICLE TYPES INCLUDED \\ ARTICLE TYPES EXCLUDED}

Medline, Google Scholar, EMBASE, CINAHIL, Ovid

English, French, Spanish, German, Italian

Oxford Centre of EBM, levels I, II, III, IV

"Reverse total shoulder arthroplasty" or "reverse total shoulder replacement" or "reverse total shoulder prosthesis" and "research models" or "biomechanical models" or "physical simulators" or "virtual simulators"

Biomechanical studies; cadaveric studies; basic science studies

Models that only pull on tendons to determine pullout strengths; literature reviews; systematic reviews; meta-analyses; case reports; case series; studies on tumors; studies on animals; technical notes; letters to editors; committee communications; book chapters 
Table 2. Physical simulators.

\begin{tabular}{|c|c|c|c|}
\hline Author & Research model & $\begin{array}{l}\text { Reverse total shoulder } \\
\text { arthroplasty (RTSA) }\end{array}$ & Aspects studied \\
\hline Kwon et al. (31) & $\begin{array}{l}\text { The New York University } \\
\text { (NYU) cadaveric shoulder } \\
\text { model }\end{array}$ & $\begin{array}{l}\text { Delta III and Encore } \\
\text { Reverse Shoulder Prosthesis }\end{array}$ & $\begin{array}{l}\text { Glenoid fixation; joint contact } \\
\text { forces }\end{array}$ \\
\hline Ackland et al. (19) & $\begin{array}{l}\text { The University of Melbourne } \\
\text { cadaveric shoulder model }\end{array}$ & $\begin{array}{l}\text { Zimmer Trabecular Metal } \\
\text { Reverse Shoulder System }\end{array}$ & $\begin{array}{l}\text { Moment arms of the shoulder } \\
\text { musculature }\end{array}$ \\
\hline Ackland et al. (20) & $\begin{array}{l}\text { The University of Melbourne } \\
\text { cadaveric shoulder model }\end{array}$ & $\begin{array}{l}\text { Zimmer Trabecular Metal } \\
\text { Reverse Shoulder System }\end{array}$ & $\begin{array}{l}\text { Muscle and joint contact loading } \\
\text { at the glenohumeral joint }\end{array}$ \\
\hline Stephenson et al. (28) & $\begin{array}{l}\text { The University of California, } \\
\text { Los Angeles (UCLA) cadaveric } \\
\text { shoulder model }\end{array}$ & $\begin{array}{l}\text { Aequalis Reversed Shoulder } \\
\text { Prosthesis }\end{array}$ & $\begin{array}{l}\text { Effects of humeral component } \\
\text { version on impingement and } \\
\text { range of motion }\end{array}$ \\
\hline Henninger et al. (22) & $\begin{array}{l}\text { The University of Utah } \\
\text { cadaveric shoulder model } \\
\text { (UUTAH) }\end{array}$ & $\begin{array}{l}\text { Modified Aequalis Reversed } \\
\text { shoulder prosthesis }\end{array}$ & $\begin{array}{l}\text { Center of rotation offset } \\
\text { influence on range of motion }\end{array}$ \\
\hline Henninger et al. (21) & $\begin{array}{l}\text { The University of Utah } \\
\text { cadaveric shoulder model } \\
\text { (UUTAH) }\end{array}$ & $\begin{array}{l}\text { Modified Aequalis Reversed } \\
\text { shoulder prosthesis }\end{array}$ & $\begin{array}{l}\text { Effect of deltoid tension and } \\
\text { humeral version }\end{array}$ \\
\hline Gutiérrez et al. (16) & $\begin{array}{l}\text { The Tampa sawbone shoulder } \\
\text { model }\end{array}$ & $\begin{array}{l}\text { Delta III prosthesis and } \\
\text { Encore Reverse Shoulder } \\
\text { Prosthesis }\end{array}$ & $\begin{array}{l}\text { Center of rotation offset } \\
\text { influence on range of motion }\end{array}$ \\
\hline Gutiérrez et al. (10) & $\begin{array}{l}\text { The Tampa sawbone shoulder } \\
\text { model }\end{array}$ & $\begin{array}{l}\text { Delta III prosthesis and } \\
\text { Encore Reverse Shoulder } \\
\text { Prosthesis }\end{array}$ & $\begin{array}{l}\text { Best combination of implant } \\
\text { designs to improve abduction } \\
\text { and avoid impingement }\end{array}$ \\
\hline Gutiérrez et al. (11) & $\begin{array}{l}\text { The Tampa mechanical testing } \\
\text { machine }\end{array}$ & $\begin{array}{l}\text { Delta III prosthesis and } \\
\text { Encore Reverse Shoulder } \\
\text { Prosthesis }\end{array}$ & Stability factors \\
\hline Favre et al. (26) & $\begin{array}{l}\text { The Balgrist, University of } \\
\text { Zurich mechanical testing } \\
\text { machine }\end{array}$ & Delta III prosthesis & $\begin{array}{l}\text { Effect of component } \\
\text { positioning on intrinsic stability }\end{array}$ \\
\hline Vaupel et al. (33) & $\begin{array}{l}\text { The Royal Oak mechanical } \\
\text { testing machine }\end{array}$ & $\begin{array}{l}\text { Custom humeral cups made } \\
\text { from conventional ultra- } \\
\text { high molecular weight } \\
\text { polyethylene and CoCrMo } \\
\text { femoral heads }\end{array}$ & $\begin{array}{l}\text { Wear simulation of RTSA } \\
\text { systems: effect of glenosphere } \\
\text { design }\end{array}$ \\
\hline
\end{tabular}


Table 3. Virtual simulators.

\begin{tabular}{|c|c|c|c|}
\hline Author (Ref.) & Research model & $\begin{array}{l}\text { Reverse total shoulder } \\
\text { arthroplasty (RTSA) }\end{array}$ & Aspects studied \\
\hline Gutiérrez et al. (12) & $\begin{array}{l}\text { The Tampa 3D } \\
\text { computer shoulder } \\
\text { model }\end{array}$ & Virtual model of RTSA & $\begin{array}{l}\text { Humeral abduction/adduction in relation } \\
\text { to the glenoid in the scapular plane; } \\
\text { adduction deficit }\end{array}$ \\
\hline Gutiérrez et al. (17) & $\begin{array}{l}\text { The Tampa 3D } \\
\text { computer shoulder } \\
\text { model }\end{array}$ & Virtual model of RTSA & $\begin{array}{l}\text { Range of motion according to: socket } \\
\text { depth; lateral offset of the glenosphere } \\
\text { from the glenoid surface; humeral neck- } \\
\text { shaft angles; location of the glenosphere on } \\
\text { the glenoid surface }\end{array}$ \\
\hline Gutiérrez et al. (18) & $\begin{array}{l}\text { The Tampa 3D } \\
\text { computer shoulder } \\
\text { model }\end{array}$ & Virtual model of RTSA & $\begin{array}{l}\text { Comparison of concentric glenospheres } \\
\text { with neutral offset and eccentrically offset } \\
\text { glenospheres }\end{array}$ \\
\hline Virani et al. (30) & $\begin{array}{l}\text { The Tampa 3D } \\
\text { computer shoulder } \\
\text { model }\end{array}$ & Virtual model of RTSA & $\begin{array}{l}\text { Effect of: humeral implant type; } \\
\text { glenosphere diameter; glenosphere } \\
\text { placement; glenosphere center of rotation } \\
\text { offset; humeral neck-shaft angle; humeral } \\
\text { offset }\end{array}$ \\
\hline $\begin{array}{l}\text { Kontaxis and Johnson } \\
\text { (27) }\end{array}$ & $\begin{array}{l}\text { The Newcastle 3D } \\
\text { shoulder model }\end{array}$ & Delta III prosthesis & $\begin{array}{l}\text { Lengthening and moment arms of deltoid } \\
\text { and rotator cuff muscles; muscle and joint } \\
\text { contact forces; prediction of impingement }\end{array}$ \\
\hline Sutton et al. (24) & $\begin{array}{l}\text { The SUNY Upstate } \\
\text { Medical University } \\
\text { 3D computer shoulder } \\
\text { model }\end{array}$ & $\begin{array}{l}\text { Aequalis Reversed } \\
\text { shoulder prosthesis }\end{array}$ & Optimization of glenoid fixation \\
\hline de Wilde et al. (29) & $\begin{array}{l}\text { Ghent } 2 \mathrm{D} \text { computer } \\
\text { shoulder model }\end{array}$ & Delta-CTA prosthesis & $\begin{array}{l}\text { Avoidance of the problem of scapular } \\
\text { notching }\end{array}$ \\
\hline Herrmann et al. (23) & $\begin{array}{l}\text { Berlin 3D computer } \\
\text { shoulder model }\end{array}$ & $\begin{array}{l}\text { Polycarbonate resin } \\
\text { model of a RTSA }\end{array}$ & $\begin{array}{l}\text { Origin-to-insertion distance and moment } \\
\text { arms of the subscapularis and teres minor } \\
\text { muscles during glenohumeral abduction }\end{array}$ \\
\hline Berton et al. (32) & $\begin{array}{l}\text { The Newcastle 3D } \\
\text { shoulder model }\end{array}$ & Delta III prosthesis & $\begin{array}{l}\text { Effect of humeral version on teres minor } \\
\text { muscle moment arm, length, and } \\
\text { impingement in reverse shoulder } \\
\text { arthroplasty during activities of daily living }\end{array}$ \\
\hline Gulotta et al. (25) & $\begin{array}{l}\text { The Hospital for } \\
\text { Special Surgery } \\
\text { (HSS) 3D computer } \\
\text { shoulder model }\end{array}$ & $\begin{array}{l}\text { Biomet Comprehensive } \\
\text { Reverse Total Shoulder } \\
\text { Replacement }\end{array}$ & $\begin{array}{l}\text { Humeral component retroversion and its } \\
\text { influence on shoulder range of motion } \\
\text { and function }\end{array}$ \\
\hline
\end{tabular}




\section{Physical simulators}

\section{Cadaver models}

Historically, cadaver models were the first research models developed for investigating the biomechanical properties of RTSAs. The New York University (NYU) shoulder model (31) was the first reported in the literature. This model consists of a custom steel ring and an MTSR (MTSR Systems, Eden Prairie, Minnesota) cyclical loading machine. The custom steel ring loads the cadaveric shoulder, fixing the scapula, while the humerus is able to move, allowing simulation of arm movements in space. The MTSR cyclical loading machine is a micro-motion testing apparatus used to measure the shear forces applied to the glenoid in order to evaluate implant fixation, cyclical micromotion and total migration. Kwon et al. (31) used the NYU shoulder model to evaluate the differences between the Delta III (DePuy Orthopaedics, Warsaw, IN, USA) and the Encore Reverse Shoulder Prosthesis (Encore Medical, LP, Austin, Texas, USA) in terms of joint contact forces and glenoid micro-motion.

The Melbourne University shoulder model $(19,20)$ is another cadaveric model of RTSA, consisting of a custom-built dynamic shoulder testing apparatus in which it is possible to load the scapula and humerus of cadaver specimens and also simulate muscle-tendon unit tension during motion testing. Indeed, each muscle is connected with a nylon line passed through a series of pulleys to a free hanging weight, and each pulley can be positioned on a rotatory frame reproducing the line of action of each muscle present in the model. Moreover, the model is used in association with the Vicon motion capture system (Vicon, Oxford, United Kingdom), which makes it possible to evaluate glenohumeral joint motion. This model was used by Ackland et al. (19) to measure the moment arms of the shoulder musculature after implantation of the Zimmer Trabecular Metal Reverse Shoulder System (Zimmer, Warsaw, IN, USA) and to compare muscle and joint contact loading of the normal shoulder versus the RTSA implanted shoulder (20).

Another cadaveric model of RTSA was created by the University of California, Los Angeles (UCLA) (28). This model consists of a custom testing apparatus in which both the scapula and the humerus of cadaveric specimens are loaded. Even though the scapula is blocked and fixed to the custom testing apparatus with the medial border perpendicular to the floor, the humerus is mounted on a rod for use, thereby making it possible to measure the ROM of the arm.

Furthermore, the shoulder can be taken through a rotational ROM at $0^{\circ}, 30^{\circ}$ and $60^{\circ}$ of glenohumeral abduction in the scapular plane. In this model, the RC muscles are absent, while the deltoid is loaded at $30 \mathrm{~N}$ and the pectoralis major and the latissimus dorsi/teres major are loaded at $15 \mathrm{~N}$. The UCLA model was used by Stephenson et al. (28) to evaluate the effect of humeral component version in the Aequalis Reversed Shoulder Prosthesis (Tornier, Edina, MN, USA) on impingement-free ROM.

The University of Utah shoulder model (UUTAH) $(21,22)$ was developed to study various aspects of RTSA. This model consists of a biomechanical shoulder simulator in which a cadaveric shoulder is loaded. The scapula is embedded in a two-part catalyzed polymer resin (3M, St. Paul, MN, USA) and oriented within the embedding block in a position calculated after the reconstruction of $\mathrm{CT}$ images of each scapula using the MIMICS program (Materialise, Leuven, Belgium). The elbow is fixed with pins located in the humerus and ulna to test the influence of straight arm and arm flexion at $90^{\circ}$, while the wrist is splinted and wrapped in Coban (3M Corporation, St. Paul, MN, USA) to stabilize the forearm. Using pneumatic cylinders (Bimba, Monee, IL, USA), the arm can be manipulated applying excursion forces to the deltoid lines. Electromechanical encoders (Celesco, Chatsworth, CA, USA) monitor the position of the cylinders while in-line load cells (Omega Technologies, Stamford, CT, USA) record the applied force. Furthermore, muscle tension can be simulated by using lightweight No. 3, stretch-resistant, braided cords (300 lb [136 kg] test Spectra Fiber 2000, WSK, Pittsburgh, PA, USA) attached to the deltoid tuberosity for the anterior, middle and posterior deltoid, while other Spectra cords are sutured to the insertions of the subscapularis, supraspinatus and infraspinatus/teres minor using No. 2 FiberWire (Arthrex, Naples, FL, USA), to simulate the tension of each respective muscle. The UUTAH shoulder model was used by Henninger et al. $(21,22)$ to evaluate the effect of lateralization of center of rotation (COR) on adduction and external rotation ROM in RTSA (22), as well as on joint stability and the dislocation forces (22), and the effect of deltoid tension and humeral version in RTSA (21). 
Bone substitute models

The first bone substitute shoulder model developed to evaluate the biomechanical characteristics of RTSAs was developed in Tampa at the University of South Florida (10, 16). The Tampa sawbones shoulder model consists of three surrogate bone models with the bone surrogate scapula clamped to a custom-made testing apparatus. The bone surrogate scapula is oriented to simulate the $30^{\circ}$ angle of the scapular plane, reproducing the physiological orientation of the scapula in relation to the rib cage, while the coracoid process is rotated anteriorly along the frontal plane. The distal portion of the surrogate humerus is connected to a movable sled by a cable through a series of pulleys, providing the motion of the arm. Additionally, a goniometer (Eval System; Green Leaf Medical, Palo Alto, CA, USA) is attached to the humerus using a metal ring restricting abduction of the humerus to the scapular plane. Muscle resistance is simulated with nylon cables attached on the humerus at the insertion point of the infraspinatus and subscapularis, and fed through eyelet screws attached to the point on the scapula identified as the center for the origin of the muscle bundle. The ends of the nylon cables are connected to a 1-kg weight to guarantee tension to the system and allow movement in the scapular plane, while an additional 1-kg weight is attached to the distal end of the humerus to provide resistance to abduction. Furthermore, this model also uses a silicon spray in the joint to simulate the synovial fluid. The Tampa shoulder sawbones model was first used to evaluate the effect of changes in the COR offset of the Encore Reverse Shoulder Prosthesis (Encore Medical, Austin, TX, USA) and of the Delta III prosthesis (DePuy Orthopaedics, Warsaw, IN, USA) on abduction ROM (16). Then, Gutierrez et al. (10) used the Tampa shoulder to compare ROM and inferior scapular impingement with the following variables: glenosphere diameter, COR offset, glenosphere position on the glenoid, and humeral neck-shaft angle.

\section{Mechanical testing machines}

Mechanical testing machines have been used mainly to evaluate the factors that may affect the stability of RTSA implants. The first mechanical testing machine was developed in Tampa, at the University of South Florida (11). This machine consists of a custom biaxial testing apparatus that makes it possible to measure
RTSA intrinsic stability. Gutiérrez et al. (11) used the Tampa mechanical testing machine to test the stability of six Encore Reverse Shoulder Prostheses (Encore Medical Corp, Austin, TX) and two Delta III prostheses (DePuy Orthopaedics, Warsaw, IN, USA), analyzing joint compressive force, prosthetic socket depth, and glenosphere size in relation to stability of the RTSA.

Another mechanical testing machine was developed at the Balgrist University of Zurich (26). The Balgrist mechanical testing machine consists of a mechanical apparatus that is able to simulate the two translational degrees of freedom of the shoulder (inferior to superior and medial to lateral). To simulate these translational degrees, the glenosphere is fixed on two linear tables (SFERAX SA, Cortaillod, Switzerland) on which a constant compressive load of $40 \mathrm{~N}$ is applied from medial to lateral, using a weight and pulley attached to the corresponding linear table. Favre et al. (26) used this mechanical testing machine to correlate the stability ratio of Delta III (DePuy Inc, Warsaw, IN, USA) with modifications in the glenoid component version (from $20^{\circ}$ retroversion to $20^{\circ}$ anteversion in $10^{\circ}$ steps) and in humeral component version (neutral, $10^{\circ}$, and $20^{\circ}$ retroversion for each glenoid version tested).

In the orthopedic research department of the Beaumont Health System, Royal Oak, MI, a wear simulation testing machine was developed to investigate RTSA stability (33). The Royal Oak testing machine is made of custom fixtures fabricated to interface the RTSA components with an MTS Bionix 12-station hip wear simulator (MTS, Eden Prairie, MN, USA). Vaupel et al. (33) used this model to investigate wear simulation and its relationship with glenosphere design. The RTSA components used were: $36 \mathrm{~mm}$ CoCrMo femoral heads (V-40; Stryker Orthopaedics, Mawah, NJ, USA) used as glenospheres and custom humeral cups manufactured from conventional ultrahigh molecular weight polyethylene (UHMWPE, GUR 1050). The Royal Oak model allows simulation of glenohumeral abduction from 44 to $90^{\circ}$ and of glenohumeral flexion from 0 to $46^{\circ}$.

\section{Virtual simulators}

The first 3D computer model of RTSA was developed in Tampa at the University of South Florida (12, 17, 18, 30). The Tampa computer model was built using a computer-aided design $(\mathrm{CAD})$ program called 
SolidWorks (SolidWorks, Concord, Massachusetts, USA) and it consists of a scapula fixed on a mounting block, a glenosphere, a humerosocket, and a humeral shaft fixed in a humerus. CT images of a Sawbones shoulder model (Pacific Research Laboratories, Vashon, Washington) were used to virtually reproduce the scapula and humerus, and the images obtained were converted into a stereolithography file using the MIMICS program (Materialise, Leuven, Belgium). The scapula and humerus of 11 patients who had had a RTSA and a preoperative CT scan were used to anatomically validate the Sawbones model. Moreover, images of each patient's scapula and the Sawbones scapula were imported into SolidWorks as 3D virtual models. The mechanical validation of the model was done by comparing the impingement-free abduction ROM in the virtual simulations with the impingementfree abduction ROM in another experimental shoulder simulator model (10) for 27 combinations obtained through modification of COR lateral offsets, glenosphere diameters and humeral neck-shaft angles. Gutiérrez et al. (12) were the first to use the Tampa computer model to evaluate humeral abduction/ adduction in relation to the glenoid in the scapular plane and to measure impingement-free abduction ROM. The same model was also used to evaluate the influence of socket depth on ROM (17). The Authors evaluated impingement-free ROM in RTSA simulating six articular constraints, defined by normalized socket depths. Moreover, the following independent variables were studied: glenosphere diameter, lateral offset of the glenosphere from the glenoid surface, humeral neck-shaft angles, and locations of the glenosphere on the glenoid surface.

Gutiérrez et al. (18) used this model to compare concentric glenospheres with neutral offset with eccentrically offset glenospheres $(6 \mathrm{~mm}$ inferior or $6 \mathrm{~mm}$ lateral) in three baseplate tilts: $15^{\circ}$ inferior, neutral and $15^{\circ}$ superior. Virani et al. (30) also used the Tampa 3D computer shoulder model to analyze ROM and impingement in relation to the following variables: humeral implant type, glenosphere diameter, glenosphere placement, glenosphere COR offset, humeral neck-shaft angle and humeral offset.

The Newcastle shoulder model is another 3D computer model used to study RTSA biomechanics (27, 32). This model was created by modifying the Newcastle upper limb model, and it is composed of six rigid bones: thorax, clavicle, scapula, humerus, radius and ulna. The complete model includes 31 muscles and three ligaments, works through inverse dynamics, and predicts muscle and joint contact forces (34). Cuff tear arthropathy (CTA) can be simulated in the model by excluding the corresponding muscle lines of action. Kontaxis and Johnson (27) developed the 3D Newcastle reverse shoulder model: they focused on lengthening and moment arms of deltoid and RC muscles, predicted muscle and joint contact forces during standardized activities, abduction, forward flexion and arm elevation ROM, and prediction of impingement. This model was also used to evaluate the effect of humeral version on teres minor muscle moment arm, length and impingement in RTSA (32). Another 3D computer model of RTSA was developed at the SUNY Upstate Medical University of New York. The SUNY model was built after implantation of the Aequalis Reversed shoulder prosthesis (Tornier, Inc., Edina, MN, USA) into models of six cadaver shoulders, and it was modeled using SolidWorks (SolidWorks Corp., Concord, MA, USA) CAD software. Moreover, CT scans were performed using a 1$\mathrm{mm}$ slice thickness in four shoulders and a 2-mm slice thickness in the remaining two shoulders. Additionally, CAD models were created from each CT scan, and the selected RTSA was implanted virtually into each CAD model, after initial reaming and then after additional incremental reaming had been performed. Sutton et al. (24) used the SUNY 3D computer shoulder model to evaluate the optimization of glenoid fixation in RTSA.

The only 2D computer model of RTSA was developed at Ghent University Hospital. The Ghent 2D computer model (29) was built using the anatomical data of 200 scapulae and the anterior-posterior view of the glenoid cavity, the infraglenoid tubercle, and the lateral border of the scapula. This $2 \mathrm{D}$ computer model was implanted with the Delta-CTA prosthesis. In this model it is possible to change the position of the glenoid component, as well as several design features such as the size of the glenosphere and the COR of the Delta-CTA prosthesis, humeral component characteristics, the depth of the polyethylene insert, and the humeral neck-shaft angle. This model was used by de Wilde et al. (29) to study the best way to avoid scapular notching. They evaluated the adduction angle in the scapular plane between the humerus and 
a vertical line parallel to the glenoid plane, defined as the plane formed by the rim of the inferior quadrants of the glenoid, when a conflict between the polyethylene cup and the scapular pillar occurred. Furthermore, they determined when the conflict between the humeral component and the scapula would appear on the scapular pillar and also whether the conflict was with the inner or the outer polyethylene cup diameter. In summary, the most important parameters evaluated were: change in the angle of the humeral neck-shaft inclination, change in the depth of the polyethylene cup, lateralization of the COR, downward glenoid inclination, increase in glenosphere radius, and inferior prosthetic overlap with the glenoid bone.

The Center for Musculoskeletal Surgery of the Charité-Universitätsmedizin of Berlin developed another 3D computer shoulder model (23). This model was built using seven fresh frozen human shoulders. The cadaveric shoulders were deprived of muscles, except for the origins and insertions of the subscapularis and teres minor. Then, the bony insertion sites of the two muscles were marked with radioopaque markers, and bony landmarks such as the medial and lateral epicondyle, angulus acromialis, trigonum scapulae and angulus inferior were also marked. Thin-sliced CT scans (Aquilion 64, Toshiba Medical Systems; Toshiba, Tokyo, Japan) with a resolution of $512 \times 512$ and a slice thickness of $0.5 \mathrm{~mm}$ were performed. 3D data visualization, analysis and modeling software (AMIRA; Mercury Computer Systems, Chelmsford, MA, USA) was used to capture the spatial position of all previously marked landmarks, thus permitting the creation of the humerus and the scapula in the 3D computer model. All shoulders were then implanted with a polycarbonate resin model of a RTSA (Mathys AG, Bettlach, Switzerland) with the humeral component in $10^{\circ}$ of retroversion and the glenoid component implanted so that a slight inferior overhang could be observed. The Berlin 3D computer shoulder model was used by Herrmann et al. (23) to analyze how RTSA changes the origin-toinsertion distance and the moment arms of the subscapularis and teres minor muscles during glenohumeral abduction. Pre- and postoperative moment arms as well as origin-to-insertion distance for subscapularis and teres minor were specifically evaluated. The Hospital for Special Surgery (HSS) 3D computer shoulder model (25) was also used to analyze the bio- mechanics of RTSA. This model (25) was built using six cadaveric shoulders that were studied with CT imaging and were then dissected of soft tissues, preserving only the tendinous attachments. Moreover, the CT images obtained were converted into 3D models, and the amount of internal and external rotation was determined with computer modeling at various scaption angles. After the imaging study, a Biomet Comprehensive Reverse Total Shoulder Replacement (Biomet Inc, Warsaw, IN, USA) was implanted in 0, 20,30 , and $40^{\circ}$ of retroversion, and the shoulders were mounted on a simulator to determine the muscle forces required to achieve 30 and $60^{\circ}$ of scaption. The HSS 3D computer shoulder model was used by Gulotta et al. (25) to analyze the effect of humeral component retroversion in RTSA on the ROM and function of the shoulder.

\section{Discussion}

The past decade has seen a considerable increase in the use of research models of RTSA. The most useful information about the relationship with postoperative outcomes and prosthetic positioning, stability factors, COR offset, best humeral version, neck-shaft angle and socket depth has been obtained through these models. The cadaver shoulder models currently used are the NYU model (31), the Melbourne model $(19,20)$, the UCLA model (28) and the UUTAH model $(21,22)$. In the NYU (31), UCLA and UUTAH models $(21,22)$ the scapula is fixed on a custom testing apparatus, with the result that the kinematics of the scapula, acromioclavicular and sternoclavicular joint is not reproduced together with that of the glenohumeral joint. On the contrary, the Melbourne model $(19,20)$ reproduces the rotatory movement of the scapula during humeral abduction using a rotatory frame. The CTA is simulated in all the cadaveric models considered, except the UUTAH model, in which the static $\mathrm{RC}$ loads are estimated from a physiological model and the muscle tension of the shoulder muscles is simulated using lightweight, stretch-resistant, braided cords. In both the UCLA model and the Melbourne model, the latissimus dorsi, pectoralis major, teres minor and deltoid are preserved, and in the Melbourne model the lines of action and the muscle-tendon unit tension of these muscles are also simulated using 
nylon lines. Instead, in the NYU model the only active muscle is the deltoid.

The only bone substitute model used to study RTSA is the Tampa sawbones shoulder model $(10,16)$. This model reproduces the physiological orientation of the scapula in relation to the rib cage, and the humerus is connected to a movable sled by a cable through a series of pulleys, providing the motion of the arm. Infraspinatus and subscapularis muscle resistance, such as the resistance of these muscles to abduction of the humerus, is simulated using nylon cables connected with a 1-kg weight. Moreover, a silicon spray simulates the synovial fluid of the glenohumeral joint. The mechanical testing machines, namely the Tampa (11), Balgrist (26) and Royal Oak (33) machines, serve to assess stability factors in RTSA. Both the Tampa and the Balgrist mechanical testing machines are biaxial testing apparatuses that are able to simulate the two translational degrees of freedom of the shoulder. However, in the Balgrist model the glenoid component can translate in the medial to lateral and inferior to superior directions. On the other hand, the Royal Oak mechanical testing machine is a custom fixture fabricated to study the RTSA using a MTS Bionix 12station hip wear simulator.

In recent years, computer models have become the option most commonly used to evaluate RTSA biomechanics. These models can be considered the "last generation" of RTSA research models, and they are derived from previously validated anatomical, mechanical or cadaveric models. The 3D computer models are the most common, while only the Ghent (29) is a $2 \mathrm{D}$ computer model. The Newcastle $(27,32)$, SUNY (24), Berlin (23) and HSS (25) computer models were developed reconstructing CT images obtained from cadaveric shoulders. The cadavers used numbered six in the case of the HSS and SUNY models, and seven in the Berlin model, while in the Newcastle model only one cadaveric specimen was used. On the other hand, the Tampa model was built after anatomical and mechanical validation of the Tampa sawbones shoulder model $(10,16)$. The Ghent model (29) was obtained using anatomical data of 200 scapulae considering the following points of interest: the angle between the glenoid plane and the scapular pillar, the distance between the COR and the inferior glenoid rim, the distance between the COR and the glenoid plane, the diameter of the glenosphere, the down- ward inclination of the glenosphere, the humerus neck-shaft angle, and the depth of the conforming polyethylene cup.

Computer models may also differ in terms of the bones, joints and tendon-muscle structures represented. In the Tampa 3D computer model, like the HSS and Ghent models, the scapula, humerus and prosthesis components are represented. In the SUNY model, only the glenoid and the glenosphere are represented. In the Newcastle model, the thorax, clavicle, scapula, humerus, radius and ulna are represented. Furthermore, the sternoclavicular and acromioclavicular joint are simulated, making it possible to take into account the kinematics of these joints during glenohumeral motion. In the complete Newcastle 3D computer model, 31 muscles and three ligaments are present. On the contrary, the Berlin model is composed of the scapula, the humerus, the prosthetic components and the subscapularis and teres minor muscles.

The Tampa sawbones shoulder model $(10,16)$ is the only bone substitute model used to study RTSA. Although the information obtained through this model is very useful, surrogate bone cannot be considered not physiological in terms of the properties of the material of which it is composed, or in terms of muscle and arm loading.

To date, various research models have been created to study RTSAs, but none of these have been shown to completely reflect real in vivo clinical conditions, and each one presents several limitations. The most common limitation of these models is that they fail to take into account the contribution of soft tissue. Moreover, the computer models were created using CT scans: an important limit of this reconstruction method is that CT has a high level of accuracy in representing osseous anatomy but it does not offer the same precision for the study of muscle origins and insertions. Another important limitation is that most of the reported models, taking into account only glenohumeral joint motion, did not evaluate the real kinematics of the shoulder. Indeed, studies that used the UUTAH and Melbourne cadaveric models, as well as the Tampa 3D computer model, neglected sternoclavicular and acromioclavicular joint kinematics, and this situation could strongly influence the outcomes, especially when considering ROM, impingement, length and moment arms of the shoulder musculature. In the SUNY and Ghent models, the different shapes of the glenoid and of the 
inferior part of the scapula were not taken into account, respectively. These aspects would be important to assess given that the SUNY model was used to study glenoid fixation and the Ghent model to study scapular notching.

The NYU cadaveric shoulder model was useful for underlining the importance of glenoid fixation and joint contact forces, but an important limitation of this model is that it was developed using cadavers with a normal range of bone density. This condition is rare in patients that receive a RTSA, and bone density is a factor that may strongly influence the glenoid fixation. An important limitation found in the Melbourne shoulder model was that the lines of action of each muscle evaluated in the model were not based on the anatomy of the single cadavers, but were obtained from a model based on the shoulder anatomy of a single specimen. The main limitation of the UUTAH model is that the biomechanical simulator used to assess deltoid tension in relation to humeral version, as well as the influence of the COR offset, could not capture some important variables related to muscle function, such as the relationship between length and tension, the muscle contraction capacity and the dynamic change of the muscle lines of action. Instead, the major limitation of the Newcastle model is that it was obtained from only one cadaver specimen.

Even though research models have shown great efficacy as means of studying RTSA biomechanics, we are still far from attaining the ultimate research model, which simulates as closely as possible the real in vivo clinical conditions.

\section{Conclusions}

A number of research models have been developed to study RTSA, but none has been shown to completely reflect real in vivo conditions. Computer models and cadaveric models are the most commonly used. Bone substitute models have been used in a few studies. Mechanical testing machines have been used mainly to test the stability factors of RTSA (35).

Because of the limitations of each individual model, additional research is required to develop a research model of RTSA that may reduce the limitations of those presently available and increase reproducibility of this technique in the clinical setting.

\section{References}

1. Khan WS, Longo UG, Ahrens PM, et al. A systematic review of the reverse shoulder replacement in rotator cuff arthropathy, rotator cuff tears, and rheumatoid arthritis. Sports Med Arthrosc. 2011;19:366-379.

2. Mohammed AA, Frostick SP. Linked shoulder replacement: current design problems and a new design proposal. Musculoskelet Surg. 2016;100:25-29.

3. Baudi P, Campochiaro G, Serafini F, et al. Hemiarthroplasty versus reverse shoulder arthroplasty: comparative study of functional and radiological outcomes in the treatment of acute proximal humerus fracture. Musculoskelet Surg. 2014;98 Suppl 1:19-25.

4. Campochiaro G, Rebuzzi M, Baudi P, et al. Complex proximal humerus fractures: Hertel's criteria reliability to predict head necrosis. Musculoskelet Surg. 2015;99 Suppl 1:9-15.

5. Giovale M, Mangano T, Rodà E, et al. Shoulder hemiarthroplasty for complex humeral fractures: a 5 to 10 -year followup retrospective study. Musculoskelet Surg. 2014;98 Suppl 1:27-33.

6. Grassi FA, Zorzolo I. Reverse shoulder arthroplasty without subscapularis repair for the treatment of proximal humeral fractures in the elderly. Musculoskelet Surg. 2014;98 Suppl 1:5-13.

7. Iacobellis C, Berizzi A, Biz C, et al. Treatment of proximal humeral fractures with reverse shoulder arthroplasty in elderly patients. Musculoskelet Surg. 2015;99:39-44.

8. Mariotti U, Motta P, Stucchi A, et al. Stemmed versus stemless total shoulder arthroplasty: a preliminary report and short-term results. Musculoskelet Surg. 2014;98:195-200.

9. Russo R, Della Rotonda G, Cautiero F, et al., Reverse shoulder prosthesis to treat complex proximal humeral fractures in the elderly patients: results after 10-year experience. Musculoskelet Surg. 2015;99 Suppl. 1:17-23.

10. Gutiérrez S, Levy JC, Frankle MA, et al. Evaluation of abduction range of motion and avoidance of inferior scapular impingement in a reverse shoulder model. J Shoulder Elbow Surg. 2008;17:608-615.

11. Gutiérrez S, Keller TS, Levy JC, et al. Hierarchy of stability factors in reverse shoulder arthroplasty. Clin Orthop Relat Res. 2008;466:670-676.

12. Gutiérrez S, Comiskey CA 4th, Luo ZP, et al. Range of impingement-free abduction and adduction deficit after reverse shoulder arthroplasty. Hierarchy of surgical and implant-design-related factors. J Bone Joint Surg Am. 2008; 90:2606-2615.

13. Nalbone L, Adelfio R, D'Arienzo M, et al. Optimal positioning of the humeral component in the reverse shoulder prosthesis. Musculoskelet Surg. 2014;98:135-142.

14. Randelli P, Randelli F, Arrigoni P, et al. Optimal glenoid component inclination in reverse shoulder arthroplasty. How to improve implant stability. Musculoskelet Surg. 2014; 98 Suppl 1:15-18.

15. Longo UG, Franceschetti E, Petrillo S, et al. Latissimus dorsi tendon transfer for massive irreparable rotator cuff tears: a systematic review. Sports Med Arthrosc. 2011;19:428-437.

16. Gutiérrez S, Levy JC, Lee WE 3rd, et al. Center of rotation affects abduction range of motion of reverse shoulder arthroplasty. Clin Orthop Relat Res. 2007;458:78-82.

17. Gutiérrez S, Luo ZP, Levy J, et al. Arc of motion and socket depth in reverse shoulder implants. Clin Biomech. (Bristol, Avon) 2009;24:473-479. 
18. Gutiérrez S, Walker M, Willis M, et al. Effects of tilt and glenosphere eccentricity on baseplate/bone interface forces in a computational model, validated by a mechanical model, of reverse shoulder arthroplasty. J Shoulder Elbow Surg. 2011;20:732-739.

19. Ackland DC, Roshan-Zamir S, Richardson M, et al. Moment arms of the shoulder musculature after reverse total shoulder arthroplasty. J Bone Joint Surg Am. 2010;92:1221-1230.

20. Ackland DC, Roshan-Zamir S, Richardson M, et al. Muscle and joint-contact loading at the glenohumeral joint after reverse total shoulder arthroplasty. J Orthop Res. 2011;29: 1850-1858.

21. Henninger HB, Barg A, Anderson AE, et al. Effect of deltoid tension and humeral version in reverse total shoulder arthroplasty: a biomechanical study. J Shoulder Elbow Surg. 2012;21:483-490.

22. Henninger HB, Barg A, Anderson AE, et al. Effect of lateral offset center of rotation in reverse total shoulder arthroplasty: a biomechanical study. J Shoulder Elbow Surg. 2012; 21:1128-1135

23. Herrmann S, König C, Heller M, et al. Reverse shoulder arthroplasty leads to significant biomechanical changes in the remaining rotator cuff. J Orthop Surg Res. 2011;6:42.

24. Sutton LG, Werner FW, Jones AK, et al. Optimization of glenoid fixation in reverse shoulder arthroplasty using 3-dimensional modeling. J Shoulder Elbow Surg. 2010;19:664-669.

25. Gulotta LV, Choi D, Marinello P, et al. Humeral component retroversion in reverse total shoulder arthroplasty: a biomechanical study. J Shoulder Elbow Surg. 2012;21:1121-1127.

26. Favre P, Sussmann PS, Gerber C. The effect of component positioning on intrinsic stability of the reverse shoulder arthroplasty. J Shoulder Elbow Surg. 2010;19:550-556.
27. Kontaxis A, Johnson GR. The biomechanics of reverse anatomy shoulder replacement-a modelling study. Clin Biomech (Bristol, Avon). 2009;24:254-260.

28. Stephenson DR, Oh JH, McGarry MH, et al. Effect of humeral component version on impingement in reverse total shoulder arthroplasty. J Shoulder Elbow Surg. 2011;20:652658.

29. de Wilde LF, Poncet D, Middernacht B, et al. Prosthetic overhang is the most effective way to prevent scapular conflict in a reverse total shoulder prosthesis. Acta Orthop. 2010; 81:719-726.

30. Virani NA, Cabezas A, Gutiérrez S, et al. Reverse shoulder arthroplasty components and surgical techniques that restore glenohumeral motion. J Shoulder Elbow Surg. 2013;22:179187.

31. Kwon YW, Forman RE, Walker PS, et al. Analysis of reverse total shoulder joint forces and glenoid fixation. Bull NYU Hosp Jt Dis. 2010;68:273-280.

32. Berton A, Gulotta LV, Petrillo S, et al. The effect of humeral version on teres minor muscle moment arm, length, and impingement in reverse shoulder arthroplasty during activities of daily living. J Shoulder Elbow Surg. 2015;24:578-586.

33. Vaupel ZM, Baker KC, Kurdziel MD, et al. Wear simulation of reverse total shoulder arthroplasty systems: effect of glenosphere design. J Shoulder Elbow Surg. 2012;21:1422-1429.

34. Charlton IW, Johnson GR. A model for the prediction of the forces at the glenohumeral joint. Proc Inst Mech Eng H. 2006;220:801-812.

35. Longo UG, Petrillo S, Berton A, Denaro V. Reverse total shoulder arthroplasty for the management of fractures of the proximal humerus: a systematic review. Musculoskelet Surg. 2016 Aug;100(2):83-91. 